\title{
INTEGRATION OF EXTERNAL AND INTERNAL DOSIMETRY IN SWITZERLAND
}

\author{
D. Frei ${ }^{1, *}$, C. Wernli ${ }^{2}$, S. Baechler ${ }^{3}$, G. Fischer ${ }^{1}$, H. Jossen ${ }^{4}$, A. Leupin ${ }^{5}$, Y. Lörtscher ${ }^{6}$, \\ R. Mini ${ }^{7}$, T. Otto ${ }^{8}$, R. Schuh ${ }^{9}$ and U. Weidmann ${ }^{10}$ \\ Expert Group on Dosimetry, Swiss Federal Commission for Radiological Protection and \\ Monitoring of Radioactivity in the Environment \\ ${ }^{1}$ BAG, Federal Office of Public Health, Bern, Switzerland \\ ${ }^{2}$ PSI, Paul Scherrer Institute, Villigen, Switzerland \\ ${ }^{3}$ IRA, Institute of Applied Radiophysics, Lausanne, Switzerland \\ ${ }^{4}$ Suva, Swiss National Accident Insurance Fund, Luzern, Switzerland \\ ${ }^{5}$ HSK, Federal Nuclear Safety Inspectorate, Villigen, Switzerland \\ ${ }^{6}$ NAZ, National Emergency Operations Centre, Zürich, Switzerland \\ ${ }^{7}$ Inselspital, University of Bern, Switzerland \\ ${ }^{8}$ CERN, Geneva, Switzerland \\ ${ }^{9}$ Mühleberg Nuclear Power Station, Mühleberg, Switzerland \\ ${ }^{10}$ Beznau nuclear power station, Döttingen, Switzerland
}

Individual monitoring regulations in Switzerland are based on the ICRP60 recommendations. The annual limit of $20 \mathrm{mSv}$ for the effective dose applies to the sum of external and internal radiation. External radiation is monitored monthly or quarterly with TLD, DIS or CR-39 dosemeters by 10 approved external dosimetry services and reported as $H_{\mathrm{p}}\left(\mathbf{1 0 )}\right.$ and $H_{\mathrm{p}}(0.07)$. Internal monitoring is done in two steps. At the workplace, simple screening measurements are done frequently in order to recognise a possible incorporation. If a nuclide dependent activity threshold is exceeded then one of the seven approved dosimetry services for internal radiation does an incorporation measurement to assess the committed effective dose $\mathbf{E}_{50}$. The dosimetry services report all the measured or assessed dose values to the employer and to the National Dose Registry. The employer records the annually accumulated dose values into the individual dose certificate of the occupationally exposed person, both the external dose $H_{\mathrm{p}}(10)$ and the internal dose $E_{50}$ as well as the total effective dose $E=H_{\mathrm{p}}(10)+E_{50}$. Based on the national dose registry an annual report on the dosimetry in Switzerland is published which contains the statistics for the total effective dose, as well as separate statistics for external and internal exposure.

\section{INTRODUCTION}

The radiation protection regulations in Switzerland are based on the ICRP60 recommendation ${ }^{(1)}$ of 1990. The regulations relevant for individual monitoring are

- Radiological Protection Act (1991)

- Radiological Protection Ordinance (1994)

- Dosimetry Ordinance (1999)

The annual dose limits for persons occupationally exposed to ionising radiation are

- $20 \mathrm{mSv}$ for the effective dose

- $500 \mathrm{mSv}$ for the skin and for extremities

- $150 \mathrm{mSv}$ for the eye lens

The annual limit of $20 \mathrm{mSv}$ for the effective dose applies to the sum of external and internal radiation.

This paper concentrates on the assessment of the effective dose by monitoring the personal dose equivalent $H_{\mathrm{p}}(10)$ and the committed effective dose $E_{50}$. The total effective dose $E$ is set to the sum of

${ }^{*}$ Corresponding author: daniel.frei@bag.admin.ch
$H_{\mathrm{p}}(10)$ and $E_{50}$. Monitoring of partial body doses (skin, extremities) is not covered here.

\section{PARTIES INVOLVED IN DOSIMETRY}

\section{Persons}

In Switzerland persons occupationally exposed to ionising radiation are defined as persons who might accumulate an effective dose of $>1 \mathrm{mSv} \mathrm{y}^{-1}$ through controllable radiation on account of their professional activity or training, or who work or undergo training regularly in controlled areas. They have to be individually monitored for radiation exposure.

\section{Authorities}

There are three authorities in Switzerland that are involved in individual monitoring:

- Federal Office of Public Health (BAG)

- National Accident Insurance Fund (Suva)

- Federal Nuclear Safety Inspectorate (HSK) 
These authorities play different roles in radiation protection (Table 1).

\section{Enterprises}

Enterprises working with ionising radiation need to have a license. One requirement of the license is the duty for individual monitoring of all the employees that are exposed to ionising radiation.

\section{Experts}

The enterprise must have a person responsible for radiation protection. This person designates the employees who are occupationally exposed to ionising radiation based on the above definition. She or he is also responsible for recording the dose values into the individual dose documents.

\section{Dosimetry services}

Currently there are 13 approved dosimetry services in Switzerland, of these 10 are approved for external and 7 for internal radiation. The approval is valid for specific measurement methods (and nuclides for internal monitoring). Table 2 shows a list of all dosimetry services and the measurement methods they use.

\section{MONITORING}

The enterprise is responsible for the individual monitoring of all its employees that are occupationally exposed to ionising radiation. It contacts one or more dosimetry services to order dosemeters or to arrange for incorporation measurements.

Figure 1 shows an overview of external and internal individual monitoring in Switzerland.

Aircrew members are not individually monitored.

\section{External exposure}

Monitoring for external radiation is done monthly with individual dosemeters. The types of dosemeters used in Switzerland are thermoluminescent dosimeters (TLDs), DIS dosemeters and CR-39 for neutrons.

TL dosemeters are sent monthly to the enterprises by the dosimetry service. At the end of the month the enterprise sends the dosemeters back to the dosimetry service for readout and dose assessment.

DIS dosemeters are currently used only on sites that have their own dosimetry service. The monitored persons can do the readout themselves by regularly inserting the dosemeter into a reader. A colleague can do this for an absent person to ensure, at least, one monthly readout.
Table 1. Authorities for radiation protection.

\begin{tabular}{lll}
\hline Authority & $\begin{array}{c}\text { Supervision of } \\
\text { enterprises }\end{array}$ & $\begin{array}{c}\text { Approval of } \\
\text { dosimetry services }\end{array}$ \\
\hline BAG & Medicine Research & $\begin{array}{l}\text { Medicine } \\
\text { Research Industry }\end{array}$ \\
Suva & Industry & - Nuclear facilities \\
HSK & Nuclear facilities & Nuter \\
\hline
\end{tabular}

Table 2. Dosimetry services and measurement methods.

\begin{tabular}{lll}
\hline Dosimetry service & \multicolumn{1}{c}{ External } & Internal \\
\hline $\begin{array}{ll}\text { Comet } \\
\text { Pedos }\end{array}$ & TLD & \\
IRA & TLD & \\
& TLD & LSC, PC, \\
Suva & TLD, Si \\
CERN & DIS, CR-39 & LSC \\
PSI & TLD, DIS, & LSC, WBC, \\
& CR-39 & TM, Si \\
KKB & DIS & \\
KKG & TLD & \\
KKL & TLD & \\
KKM & TLD & WBC, TM \\
Basel Hospital & & WBC \\
mb-microtec & & LSC \\
RC TRITEC & & LSC \\
\hline
\end{tabular}

TLD: thermoluminescent dosemeter, DIS: direct ion storage, CR-39: etch of track, LSC: liquid scintillation counter, WBC: whole body counter, PC: proportional counter, TM: thyroid monitor, Si: Silicon detector

\section{Internal exposure}

Monitoring for internal radiation is done in two steps:

(1) Screening measurement at the workplace.

(2) Incorporation measurement by an approved dosimetry service.

At the workplace simple screening measurements are done frequently in order to recognise a possible incorporation.

If the screening measurement shows that a nuclide specific activity threshold is exceeded then one of the internal dosimetry services, which are approved for this nuclide, does an incorporation measurement to assess the committed effective dose $E_{50}$.

For many important nuclides the appendix of the dosimetry ordinance describes the procedures used for screening and for incorporation of measurements. The activity threshold was chosen such that the annual dose will be $<1 \mathrm{mSv}$ if it is never exceeded during the year. 


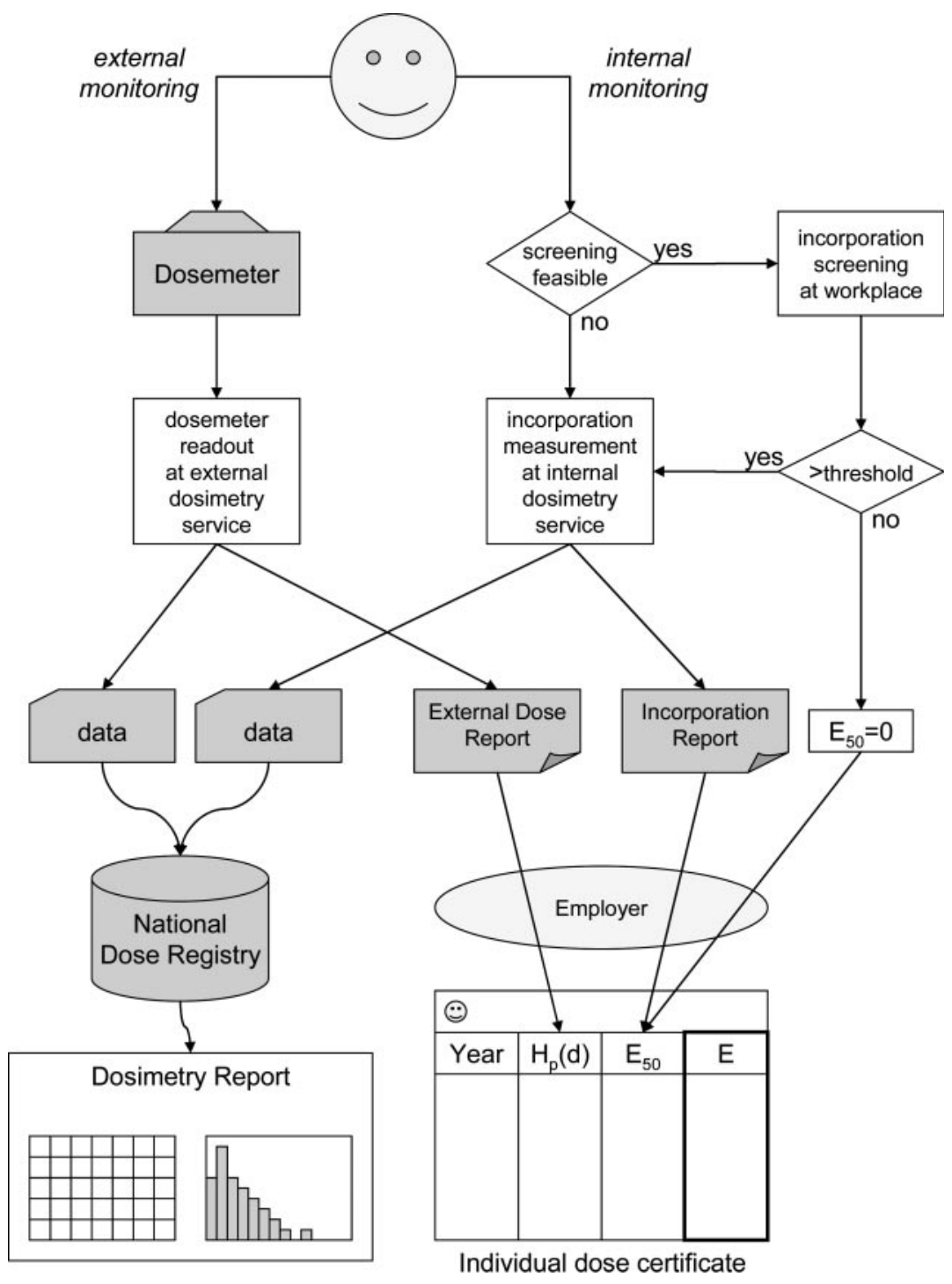

Figure 1. Overview of external and internal individual monitoring.

In practice, the screening measurements are sometimes not done separately but combined with regular incorporation measurements, e.g. liquid scintillation counting (LSC) measurements of urine.

\section{Enhanced doses}

In case a dose of $\geq 2 \mathrm{mSv}$ is measured for $H_{\mathrm{p}}(10)$ or assessed for $E_{50}$ the dosimetry service gives notice to the enterprise and to the appropriate regulatory authority which investigates the cause of the enhanced dose. The limit of $20 \mathrm{mSv}$ is exceeded typically once a year. In that case a more thorough investigation is done and a better estimate of the effective dose can be obtained based on the peculiar exposure situation.

\section{RECORDING}

The dosimetry services report all the dose values to the customer and to the national dose registry. It is possible that a person is monitored by more than one dosimetry service, e.g. one for internal radiation and another for external radiation. 


\section{FREI ET AL.}

\section{Individual dose document}

Every person who is occupationally exposed to ionising radiation has an individual dose document. The enterprise is responsible to enter the total annual doses into this document. Dose records for external and internal monitoring are possibly coming from different dosimetry services. The total effective dose $E$ is set to the sum of $H_{\mathrm{p}}(10)$ and $E_{50}$.

If there are screening measurements but no incorporation measurements for a person then the committed effective dose is recorded as $E_{50}=0$ in the dose document.

At the end of employment the dose document is given to the occupationally exposed person who has to pass it to a new employer.

\section{Temporary dose document}

For an employee who leaves the enterprise during the year a temporary dose document is filled out in addition. It contains the accumulated dose value since the beginning of the current year. At the end of the year the new employer takes it into account to calculate the total annual dose.

The temporary dose document is also used for outside workers.

\section{National dose registry}

The Federal Office of Public Health keeps a National Dose Registry that contains all the dose records from external radiation exposure in Switzerland since 1989. Since the internal dosimetry services have been approved in 2001 the registry includes also the results from incorporation measurements. The data in the registry must be conserved for a period of 100 years.

Dose records for the same person that are received from different approved dosimetry services are joined together in order to assess the total annual dose.

The registry keeps separate dose values for external $\left[H_{\mathrm{p}}(10)\right]$ and internal $\left(E_{50}\right)$ exposure. The total effective dose $E$ is available as well as the sum of $H_{\mathrm{p}}(10)$ and $E_{50}$.

For persons without incorporation measurements there is no record for $E_{50}$ in the registry even if they are monitored for internal exposure by screening.

\section{DATA PUBLICATION}

The regulatory authorities publish an annual report on the results of personal dosimetry in Switzerland. It contains dose statistics that are based on the national dose registry for the following main fields of activity:

- Hospitals

- Medical practices
- Radiological medical practices

- Dental practices

- Universities, research

- Nuclear power stations

- Industry, trade

- Public sector

- Miscellaneous

Tables 3 and 4 show a summary of the preliminary statistic for the year 2004 for external, internal and total exposure. Note that the total number of persons is less than the sum because some persons are monitored for both external and internal radiation.

\section{CONCLUSIONS}

Individual monitoring is well regulated in Switzerland for both external and internal exposure. About 1\% of the seven million inhabitants are monitored. An important purpose of individual monitoring is to show that there is no radiation exposure for most persons. In fact most of the dose values are 0 or $<1 \mathrm{mSv}$. The limit of $20 \mathrm{mSv}$ for the effective dose is exceeded typically once a year. Internal exposure contributes $\sim 1 \%$ to the collective dose. The enterprises are responsible to record the annual dose values for their employees into the individual dose documents. All monthly dose values from exposure in Switzerland are recorded in the national dose registry with the exception of the $E_{50}=0$ values that

Table 3. Dose statistics $2004^{\mathrm{a}}$ : number of persons.

\begin{tabular}{lrrr}
\hline Activity & External & Internal & Total \\
\hline Medicine & 50040 & & 50040 \\
Research & 9071 & 321 & 9117 \\
Industry & 2127 & 740 & 2610 \\
Nuclear & 3828 & 2 & 3828 \\
Other & 2393 & 2 & 2393 \\
Total & 67459 & 1065 & 67988 \\
\hline
\end{tabular}

${ }^{\text {a}}$ Preliminary

Table 4. Dose statistics $2004^{\mathrm{a}}$ : collective dose in man-Sv.

\begin{tabular}{lccc}
\hline Activity & External & Internal & Total \\
\hline Medicine & 1.08 & & 1.08 \\
Research & 0.56 & $<0.001$ & 0.56 \\
Industry & 0.20 & 0.063 & 0.26 \\
Nuclear & 4.37 & $<0.001$ & 4.37 \\
Other & 0.04 & 0 & 0.04 \\
Total & 6.25 & 0.063 & 6.31 \\
\hline
\end{tabular}

${ }^{\text {a}}$ Preliminary 
INTEGRATION OF EXTERNAL AND INTERNAL DOSIMETRY

result from incorporation screening measurements alone. Also not included in the registry are doses accumulated outside of Switzerland. Dose statistics based on the registry are published in an annual dosimetry report.

\section{REFERENCES}

1. International Commission on Radiological Protection. 1990 Recommendations of the International Commission on Radiological Protection. ICRP Publication 60 (Oxford: Pergamon Press) (1990). 